\title{
Tele-monitoring Technology as a Tool for Monitoring and Management of Patients with Congestive Heart Failure
}

\author{
Elena Vlahu-Gjorgievska \\ School of Computing and Information Technology \\ University of Wollongong \\ elenavg@uow.edu.au
}

\section{Swetha Nagapuri}

School of Computing and Information Technology

University of Wollongong

\section{Khin Than Win}

School of Computing and Information Technology

University of Wollongong

\section{Abstract}

Telehealth interventions are designed to facilitate the remote exchange of information and data between patients and health care providers, improving the quality and safety of the patients and increasing efficiency and cost-effectiveness of health care providers. The development of telecommunications and virtual technology allowed a number of telehealth systems to be applied in different health care areas. These technologies can provide an alternative monitoring and solutions for decreasing the hospital readmission rates for patients with congestive heart failure (CHF). In this paper, a systematic literature review regarding telemonitoring and its use in the management of patients with CHF is conducted. The result indicated a that standardized tele-monitoring design would reduce a length of hospitalization and re-hospitalization rate. The other factors that moderate the effectiveness of the telemonitoring intervention include quality of life, mortality rate, and disease-specific knowledge (health literacy). All these factors align with the consumer-centred principle of The Australian Safety and Quality Framework for Health Care.

Keywords: tele-monitoring; health care; health literacy; continuity of care; congestive heart failure

\section{Introduction}

Cardiovascular diseases are the number one cause of death globally. In 2013 cardiovascular disease caused 17.3 million deaths or about $32 \%$ of all deaths that year (Zipes et al., 2018). Congestive Heart Failure (CHF) is defined as a complex chronic condition where the heart pumps the blood slowly and weakens the pumping power of blood, which can result in numerous heart disease conditions like coronary artery disease, heart attack and cardiomyopathy (Velagaleti \& Vasan, 2007). This growth in the number of patients suffering from CHF leads to an increase in hospital readmissions every year. Thus, patients with heart failure need to be monitored after they have been diagnosed or discharged from the hospital to prevent progress in disease and improve their health. Tele-monitoring systems are one of the solutions that can provide the required patients' assistance in various ways (Ponikowski et al., 2014). 
Telehealth is the delivery of health care from a distance, indicating a shift from the traditional clinical contexts towards patients and where they live (Burrows, Coyle \& Gooberman-Hill, 2018). It can be cost effective and promote self-management especially to people with chronic illness (Trajkovik et al., 2014). Tele-monitoring systems allow active monitoring of patients' health parameters, provide health recommendations and educational materials, as well as clinical interventions in emergency situations. These systems can be used as a viable mechanism supporting more independent life and reducing the mortality and hospitalization for patients with heart failure (Ware, Seto \& Ross, 2018). There are other telehealth systems such as teleconsultation between healthcare providers and teleconsultations between patients and healthcare providers (Maarop \& Win 2012). The scope of this study is on telehealth systems between heart failure patients and the healthcare providers.

The Self-Determination Theory postulates of autonomy, competence and relatedness would provide the patients' behaviour of acceptance towards the tele-monitoring technology as a health care tool for patients with congestive heart failure. The study will examine whether the tele-monitoring can add a value to the patients' need for autonomy, competency and the relatedness by examining the role of tele-monitoring in strengthening patients confidence; assisting the needed behaviour change and facilitating communication between the patients and the health care providers. On the other hand, many health policies work differently with different health care systems based on their primary concerns such as economic, political and social issues (Cheow \& Win, 2007). The health system in Australia is strategically aligned with The Australian Safety and Quality Framework for Health Care (Australian Commission on Safety and Quality in Health Care, 2010) that specifies three core principles for safe and highquality care: Consumer centred, Driven by information, and Organised for safety. This Framework provides 21 areas for action that all people in the health system can take to improve the safety and quality of care provided in all health care settings. Several areas for action are related to consumer-centred health care: develop methods and models to help patients get health services when they need them; increase health literacy; partner with patients, families and carers to share decision making about their care; provide care that respects and is sensitive to different cultures; and improve continuity of care. Similarly, Hospital Quality and Safety Assurance in Victoria (Duckett, 2017) complements the Australian Safety and Quality Framework, while focusing mainly on quality assurance in the hospital environment.

The objective of this systematic literature review is to understand the role of tele-monitoring in the patients' management and improvement in the continuity of care. Since the number of patients with $\mathrm{CHF}$ is growing rapidly, tele-monitoring as a technology for monitoring and management of health parameters can greatly contribute towards the improvement of the quality of life for this vulnerable group of patients. Thus, this study is focused on the telemonitoring as a technology for the management and self-management of patients with $\mathrm{CHF}$ in the context of Self-Determination Theory (SDT) and consumer-centred principle of The Australian Safety and Quality Framework for Health Care (ASQFHC).

\section{Theoretical Perspectives}

Self-Determination Theory distinguishes between autonomous as intrinsic and wellinternalized extrinsic motivation, and controlled motivations as regulation by external factors (Ryan and Deci, 2000). Based on these motivations, SDT introduces three postulates as basic psychological needs: competence, autonomy, and relatedness. The theory underscores the idea 
that people's relationships and cultural and social contexts must involve and support their fundamental human needs based on these three postulates (Legault, 2017).

In the health context, maintenance of behaviour over time requires patients to internalize values and skills for change, and experience self-determination. Therefore, the SelfDetermination Theory is focused on the processes through which a person acquires the motivation for initiating new health-related behaviours and maintaining them over time (Ryan et al., 2008).

SDT predicts that competence (as confidence and competence to change) alone is not sufficient to ensure adherence, it must be accompanied by autonomy. Two forms of autonomous motivation are identified and integrated regulation. In identified regulation, the person identifies the value or importance of a behaviour or health practice; and in integrated regulation, the person aligns its behaviour with lifestyle patterns. According to SDT, relatedness is connected with the practitioner-patient relationship. Thus, a sense of being respected, understood, and cared for is essential for forming the experiences of connection and trust (Ryan et al., 2008).

The findings in (Ng et al., 2012) suggest that SDT can become a foundation for the development of interventions within health promotion and health care contexts. In this context, SDT principles can be included in delivering health care messages or as a guideline for more effective and more cost-effective interventions. Murray et al. (2015) apply the SDT as a base theory for their communication skills training intervention - CONNECT. Results from the investigation of Gunnell et al. (2014) point out that various components of the SDT could be targeted in order to increase wellbeing and physical activity behaviour. Hancox et al. (2018) examined the process of instructors' understanding and adopting, and the practicalities of operationalising specific SDT-informed motivational strategies within the particular context of indoor group cycling classes.

\section{Methodology}

The process of papers selection was based on the PRISMA approach (Liberati et al., 2009). The reviewed papers were selected by searching relevant publications in three electronic databases: Science Direct, Sage and Pub Med Central. These databases contain relevant papers in the field of application of tele-monitoring systems published in high-impact journals. The search terms were: ("mobile phone applications" OR "self-management") AND ("selfmonitoring" OR "tele-monitoring" OR "telehealth") AND ("heart failure" OR "congestive heart failure"). The search on the databases was conducted in February 2017.

The tele-monitoring systems are enabled by the telecommunications and information technology that have progressive developments in health care over the past several years. Thus, we have limited our search on articles published from 2010 to 2017. Also, the studies needed to meet the following criteria to be included in the review:

- A peer-reviewed article written in English,

- $\quad$ An article focused on a study or trial for patients with CHF that use tele-monitoring systems.

The review papers, conference papers, case reports, as well as the papers related to other health conditions, or health conditions in combination with $\mathrm{CHF}$ were excluded. 
Tele-monitoring, as an innovative technology for monitoring health parameters of the patients, is an emerging approach used in hospital and home environments all over the world. To have a broader picture of the systems and its impact on the patients with heart failure, we didn't exclude papers based on the country where the study/studies were conducted. All the papers that met the aforementioned criteria for inclusion and exclusion, regardless of the country, were included in this report.

The initial cross-database search resulted in 500 articles: Science Direct (125 papers), Sage (73 papers) and Pub Med Central (302 papers). From this set of articles, 342 articles were excluded based on the article title and abstract. The remaining 158 articles were assessed for eligibility by full-text and a further 147 articles were excluded based on the introduction, conclusion and full-text review as they didn't provide sufficient information on telehealth monitoring for congestive heart failure. The resulting 11 articles were included in the review. The process of the selection of the papers (PRISMA flow diagram) is presented on Figure 1.

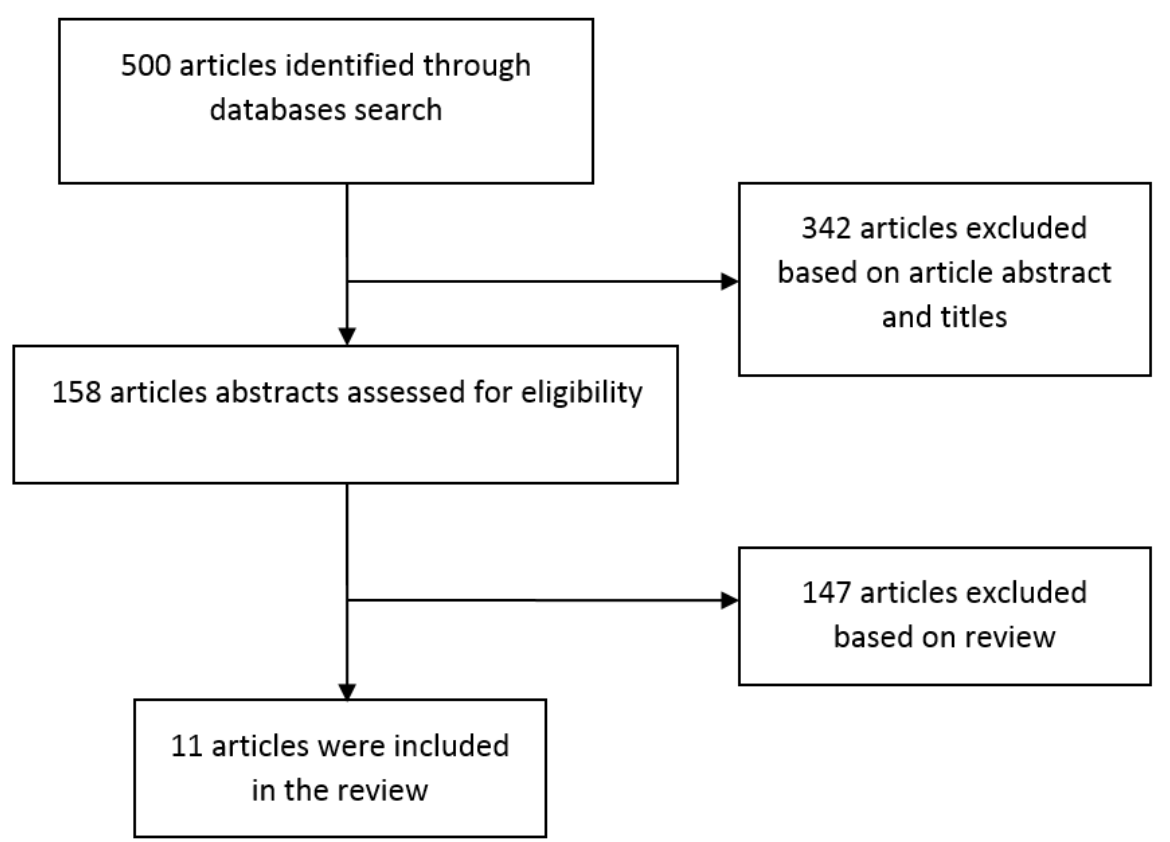

Figure 1. Overview of data extraction for selecting relevant papers

\section{Results}

In Table 1 are summarized the journals and its impact factor of the papers and studies included in this systematic review.

\begin{tabular}{|l|l|l|}
\hline \multicolumn{1}{|c|}{ Author } & \multicolumn{1}{c|}{ Journal } & \multicolumn{1}{c|}{ Impact factor } \\
\hline Black et al., 2014 & Trials & $\begin{array}{l}\text { Performance and findings of randomised } \\
\text { trials in health from BMC }\end{array}$ \\
\hline Blum \& Gottlieb, 2014 & Journal of Cardiac Failure & IF. 3.994 \\
\hline Boyne et al., 2011 & $\begin{array}{l}\text { International Journal of } \\
\text { Nursing Studies }\end{array}$ & IF 3.656 \\
\hline Cichosz et al., 2016 & Trials & $\begin{array}{l}\text { Performance and findings of randomised } \\
\text { trials in health from BMC }\end{array}$ \\
\hline Domingo et al., 2012 & $\begin{array}{l}\text { European Journal of } \\
\text { Cardiovascular Nursing }\end{array}$ & IF 2.651 \\
\hline
\end{tabular}




\begin{tabular}{|l|l|l|}
\hline \multicolumn{1}{|c|}{ Author } & \multicolumn{1}{c|}{ Journal } & \multicolumn{1}{c|}{ Impact factor } \\
\hline Eilat- Tsanani et al., 2015 & $\begin{array}{l}\text { European Journal of } \\
\text { Cardiovascular Nursing }\end{array}$ & IF 2.651 \\
\hline Ferrante et al., 2010 & $\begin{array}{l}\text { Journal of American } \\
\text { College of Cardiology }\end{array}$ & IF 16.834 \\
\hline Kao et al., 2016 & Telemedicine and e-Health & IF 2.165 \\
\hline Ong et al., 2016 & $\begin{array}{l}\text { Journal of American } \\
\text { Medical Association }\end{array}$ & IF 47.7 \\
\hline Stut et al., 2015 & $\begin{array}{l}\text { Patient Preference and } \\
\text { Adherence }\end{array}$ & IF 1.733 \\
\hline Veenstra et al., 2015 & Netherlands Health Journal & IF 1.476 \\
\hline
\end{tabular}

Table 1. Description of the included trials and studies

\subsection{Study Demographics}

The studies in the eleven reviewed papers were conducted in eight different countries (USA, Netherlands, Denmark, Spain, Israel, Argentina, United Kingdom and Germany). Most of the studies were conducted in the USA (Black et al, 2014; Blum \& Gottlieb, 2014; Kao et al., 2016; Ong et al., 2016) and two were conducted in Netherland (Boyne et al., 2011; Veenstra et al., 2015). Multi-countries study (United Kingdom, Germany and Spain) was presented in one of the papers (Stut et al., 2015). The duration period of the studies varied from 3 months to 3 years. Most of the studies used randomized control trials (Black et al., 2014; Blum \& Gottlieb, 2014; Boyne et al., 2011; Cichosz, Ehlers \& Hejlesen, 2016; Ferrante et al., 2010; Ong et al., 2016), and others are pre and post-study without using control group (Veenstra et al., 2015), prospective intervention study (Domingo et al, 2012), service-evaluation retrospective study (Eliat-Tsanani et al., 2016), observational study (Stut et al., 2015) and retrospective cohort study (Kao et al., 2016).

In all studies, tele-monitoring was performed in the home environment.

Demographic and other details of the studies covered in the reviewed papers are presented in Table 2 and Table 3.

BEAT-HF (Black et al., 2014; Ong et al., 2016) is a multi-centres randomized control trial conducted for a period of 180 days to investigate the effectiveness of transition of care to patients. 1437 participants with an average age of 73 years were selected from six academic health care centres located in California.

Cichosz, Ehlers \& Hejlesen (2016) conducted a randomized control trial for a period of 12 months in Denmark. Participants were selected from three health care centres by handing out the questionnaires that measure the quality of life based on baseline physical measurements and demographic characters. Another service-evaluation retrospective study that lasts for 12 months, conducted by Eilat-Tsanani et al. (2016) in Israel, investigated the change in the quality of life and re-hospitalisation rate of patients. Veenstra et al. (2015) conducted an optimized care program with 102 patients in the Netherlands. For two years telehealth interventions were used to evaluate the unplanned admissions, quality of life and disease-specific knowledge in the hospital. 


\begin{tabular}{|c|c|c|c|c|}
\hline Author & Study & Study Name & Country & Study Period \\
\hline $\begin{array}{l}\text { Black et al., } \\
2014\end{array}$ & $\begin{array}{l}\text { Randomized Control } \\
\text { Trial }\end{array}$ & BEAT - HF & California, USA & $\begin{array}{l}6 \text { months (180 } \\
\text { days) }\end{array}$ \\
\hline $\begin{array}{l}\text { Blum \& } \\
\text { Gottlieb, } \\
2014\end{array}$ & $\begin{array}{l}\text { Randomized Control } \\
\text { Trial }\end{array}$ & N/A & $\begin{array}{l}\text { Baltimore, } \\
\text { Washington, } \\
\text { Maryland, USA }\end{array}$ & $\begin{array}{l}26 \pm 14 \text { months } \\
(802 \pm 430 \text { days })\end{array}$ \\
\hline $\begin{array}{l}\text { Boyne et al., } \\
2011\end{array}$ & $\begin{array}{l}\text { Randomised Control } \\
\text { Trial }\end{array}$ & TEHAF & Netherlands & 12 months \\
\hline $\begin{array}{l}\text { Cichosz, } \\
\text { Ehlers \& } \\
\text { Hejlesen, } \\
2016\end{array}$ & $\begin{array}{l}\text { Randomised Control } \\
\text { Trial }\end{array}$ & $\begin{array}{l}\text { TeleCare North } \\
\text { Heart Failure } \\
\text { Trial }\end{array}$ & Denmark & 12 months \\
\hline $\begin{array}{l}\text { Domingo et } \\
\text { al., } 2012\end{array}$ & $\begin{array}{l}\text { Prospective } \\
\text { Intervention Study }\end{array}$ & CARME & Spain & 12 months \\
\hline $\begin{array}{l}\text { Eilat-Tsanani } \\
\text { et al., } 2016\end{array}$ & $\begin{array}{l}\text { Service-evaluation } \\
\text { Retrospective Study }\end{array}$ & TSCHF & Israel & 12 months \\
\hline $\begin{array}{l}\text { Ferrante et } \\
\text { al., } 2010\end{array}$ & $\begin{array}{l}\text { Randomised Control } \\
\text { Trial }\end{array}$ & DIAL & Argentina & $\begin{array}{l}16 \text { months ( } 57 \\
\text { months before / } \\
41 \text { months after) }\end{array}$ \\
\hline $\begin{array}{l}\text { Kao et al., } \\
2016\end{array}$ & $\begin{array}{l}\text { Retrospective Cohort } \\
\text { Study }\end{array}$ & HBP CMS & USA & 3 years \\
\hline $\begin{array}{l}\text { Ong et al., } \\
2016\end{array}$ & $\begin{array}{l}\text { Randomised Control } \\
\text { Trial }\end{array}$ & BETA-HF & California, USA & 6 months \\
\hline $\begin{array}{l}\text { Stut et al., } \\
2015\end{array}$ & Observational Study & Heart Cycle & $\begin{array}{l}\text { United Kingdom, } \\
\text { Germany and } \\
\text { Spain }\end{array}$ & 3 to 18 months \\
\hline $\begin{array}{l}\text { Veenstra et } \\
\text { al., } 2015\end{array}$ & $\begin{array}{l}\text { Pre and post-study } \\
\text { program without using } \\
\text { a control group }\end{array}$ & N/A & Netherlands & $\begin{array}{l}12 \text { months pre- } \\
\text { phase and } 12 \\
\text { months post- } \\
\text { phase }\end{array}$ \\
\hline
\end{tabular}

Table 2. Description of the included trials and studies

The study of Kao et al. (2016) analyses the mortality rate and hospitalization. The authors are using the Health Buddy Program (HBP) for monitoring HF patients' demographic conditions, baseline characteristics, medicare beneficiaries (cost analysis) and retrospective cohort.

The Heart Cycle study was conducted by Stut et al. (2015) at three hospitals located in UK, Germany and Spain for a period of 3 to 18 months enrolling 123 patients. This study evaluated the HF patients' adherence to self-care behaviour in telehealth system by educating and coaching the patients based on their knowledge towards the disease.

Blum \& Gottlieb (2014) conducted a randomized trial at the Medical Centre of the University of Maryland, Baltimore Veterans Administration Medical Centre and other private practices in order to identify the quality of life, change in the frequency of re-hospitalisation rate and costs. TEHAF is another randomized control trial with 390 patients (Boyne et al., 2011) for a period of 12 months at 3 medical centres located in the Netherlands.

Catalan Remote Management Evaluation (CARME) study (Domingo et al., 2012) was conducted for 12 months at University Hospital in Spain. The aim of the study was to analyse 
the improvement of the quality of life of HF patients by using Motiva Healthcare system and supporting educational motivating tools. DIAL study, presented by (Ferrante et al., 2010) is a randomized trial conducted at 51 centres in Argentina. The objective of this intervention was to support patients' health behaviours such as dietary, change in physical activity and medication adherence using telecommunication technology.

\begin{tabular}{|c|c|c|c|c|}
\hline Author & Device /System & $\begin{array}{l}\text { Monitor/Follow } \\
\text { up }\end{array}$ & Sample Size & Data Analysis \\
\hline $\begin{array}{l}\text { Black et al., } \\
2014\end{array}$ & $\begin{array}{l}\text { Ideal Life } \\
\text { Body-Manager, BP- } \\
\text { Manager, Ideal Life } \\
\text { Pod }\end{array}$ & $\begin{array}{l}\text { Nurses, } \\
\text { Cardiologists }\end{array}$ & 1500 patients & $\begin{array}{l}\text { multivariate } \\
\text { regression } \\
\text { analysis }\end{array}$ \\
\hline $\begin{array}{l}\text { Blum \& } \\
\text { Gottlieb, } \\
2014\end{array}$ & $\begin{array}{l}\text { Philips Electronic E- } \\
\text { care system }\end{array}$ & $\begin{array}{l}\text { Nurses, } \\
\text { Cardiologists }\end{array}$ & 204 patients & $\begin{array}{l}\text { t-test, chi-square } \\
\text { test, Mann Whitney } \\
\text { U test }\end{array}$ \\
\hline $\begin{array}{l}\text { Boyne et } \\
\text { al., } 2011\end{array}$ & Health Buddy & $\begin{array}{l}\text { Nurses, } \\
\text { Cardiologists }\end{array}$ & 390 patients & $\begin{array}{l}\text { t-test, } \\
\text { MAN(C)OVA }\end{array}$ \\
\hline $\begin{array}{l}\text { Cichosz, } \\
\text { Ehlers \& } \\
\text { Hejlesen, } \\
2016\end{array}$ & $\begin{array}{l}\text { Telekit - Tablet } \\
\text { connected to two } \\
\text { external devices: } \\
\text { (1)Digital Blood } \\
\text { pressure Monitor, and } \\
\text { (2)Precision Health } \\
\text { Scale }\end{array}$ & $\begin{array}{l}\text { Clinicians, } \\
\text { Nurses }\end{array}$ & 316 patients & t-test \\
\hline $\begin{array}{l}\text { Domingo } \\
\text { et al., } 2012\end{array}$ & $\begin{array}{l}\text { Motiva system \& } \\
\text { Motiva Plus (Philips) }\end{array}$ & Nurses, Doctors & 97 patients & $\begin{array}{l}\text { chi-square test, } \mathrm{t}- \\
\text { test, Wilcoxon test }\end{array}$ \\
\hline $\begin{array}{l}\text { Eilat- } \\
\text { Tsanani et } \\
\text { al., } 2016\end{array}$ & $\begin{array}{l}\text { Telemedicine system } \\
\text { with Tele weight scale }\end{array}$ & $\begin{array}{l}\text { Nurses, General } \\
\text { practitioners, } \\
\text { Cardiologists }\end{array}$ & 141 patients & $\begin{array}{l}\text { t-test, regression } \\
\text { analysis }\end{array}$ \\
\hline $\begin{array}{l}\text { Ferrante et } \\
\text { al., } 2010\end{array}$ & $\begin{array}{l}\text { Telephone } \\
\text { Interventions }\end{array}$ & $\begin{array}{l}\text { Nurses, } \\
\text { Cardiologists }\end{array}$ & 1518 patients & $\begin{array}{l}\text { Pearson chi-square, } \\
\text { t-test }\end{array}$ \\
\hline $\begin{array}{l}\text { Kao et al., } \\
2016\end{array}$ & Health Buddy & $\begin{array}{l}\text { Nurses, } \\
\text { Physicians, } \\
\text { Physician } \\
\text { assistants } \\
\end{array}$ & $\begin{array}{l}623 \text { patients (in } \\
\text { each group) }\end{array}$ & $\begin{array}{l}\text { Wilcoxon test, chi- } \\
\text { square test }\end{array}$ \\
\hline $\begin{array}{l}\text { Ong et al., } \\
2016\end{array}$ & $\begin{array}{l}\text { Equipment supplied } \\
\text { by IDEAL Life }\end{array}$ & Nurses & $\begin{array}{l}\text { Out } 1437 \\
\text { participants }\end{array}$ & $\begin{array}{l}\text { multivariable } \\
\text { analysis }\end{array}$ \\
\hline $\begin{array}{l}\text { Stut et al., } \\
2015\end{array}$ & $\begin{array}{l}\text { Motiva Telehealth } \\
\text { System (Philips) }\end{array}$ & Nurses & 123 patients & t-test \\
\hline $\begin{array}{l}\text { Veenstra et } \\
\text { al., } 2015\end{array}$ & $\begin{array}{l}\text { Motiva Telehealth } \\
\text { System (Philips) }\end{array}$ & $\begin{array}{l}\text { Nurses, } \\
\text { Cardiologists }\end{array}$ & 102 patients & $\begin{array}{l}\text { analysis of variance } \\
\text { - ANOVA }\end{array}$ \\
\hline
\end{tabular}

Table 3. Tele-monitoring systems, sample size and statistics used in the reviewed studies 
Most of the studies categorise the patients using the New York Heart Association (NYHA) functional classification. NYHA classification focuses on the exercise capacity of the patient and the symptomatic status of the disease. Based on the NYHA classification system, the estimation of HF severity can be classified as a stage two, three, or four, allowing the experts to adjust the treatment of the patient and minimize the risk of adverse events (Tripoliti et al., 2017).

Eight papers (Boyne et al., 2011; Cichosz, Ehlers \& Hejlesen, 2016; Domingo et al., 2012; EliatTsanani et al., 2016; Ferrante et al., 2010; Ong et al., 2016; Stut et al., 2015; Veenstra et al., 2015 ) included patients suffering from NYHA II, III or IV. In the Heart Cycle study (Stut et al., 2015) the mean age of the patients is above 50 years and $66 \%$ of the patients were classified as NYHA III. In the TEHAF and CARME studies, the patients were in the category of NYHA IIIV. In the study of Veenstra et al. (2015), most of the patients were diagnosed with NYHA IIIV, and in the BEAT-HF study (Ong et al., 2016) 61.2\% of the patients were under the category of NYHA III-IV.

\subsection{Cultural Background of the Participants in the Reviewed Studies}

In six papers (Black et al., 2014; Blum \& Gottlieb, 2014; Stut et al., 2015; Eliat-Tsanani et al., 2016; Cichosz, Ehlers \& Hejlesen, 2016; Ferrante et al., 2010) basic priority is the ability of the patient to handle the electronic devices. In addition, other five papers (Black et al., 2014; Stut et al., 2015; Kao et al., 2016; Domingo et al., 2012; Cichosz, Ehlers \& Hejlesen, 2016) considered patients' socio-economic and cultural factors. In the study of Cichosz, Ehlers \& Hejlesen (2016), only patients who can communicate in Danish language and be able to handle landline or mobile phone by themselves or have carers that can translate them about the use of telehealth system were included in the study. In BEAT-HF study (Black et al., 2014; Ong et al., 2016), patients speaking English, Spanish, Farsi or Russian were included. In TEHAF study (Boyne et al., 2011) only patients able to visit any of the 3 medical centres and can communicate in Dutch were included. In CARME study (Domingo et al., 2012) all patients aged above 18 years, having a television and understanding and being able to adequately carry out self-monitoring were included.

\subsection{Telehealthcare Approach}

Cichosz, Ehlers \& Hejlesen (2016) are using Telekit system comprised of Samsung Galaxy Tab 2 tablet and two external devices (digital blood pressure monitor and scale) wirelessly connected to transmit the data to the tablet. The tablet collects data from the external devices and disease-specific questionnaires, and transmit it to the central clinic system. The Telekit sends the patients a reminder and an alarm to note the baseline measurements (blood pressure, pulse rate, and weight) and fill the questionnaires on health-related quality of life. The measurements (blood pressure, pulse, and weight) and symptom-specific information (from the questionnaire) are assessed by a nurse or clinician at fixed intervals. If a patient's measurements are not received as expected or clinician observes abnormal measurements the patient will be contacted with further instructions.

Telemedicine system used in TSCHF study (Eliat-Tsanani et al., 2016) comprises of tele-weight scale and electronic medical record (EMR). A central communication module automatically transmits the patient's measurements (daily weight) to the EMR. The hospital administration gets the notification when the patient's baseline value triggers, so the medical staff can immediately contact the patients for further preventive measures. 
Blum \& Gottlieb (2014) uses the Philips Electronic E-care system to monitor and record the patient's data. Data is encrypted and wirelessly transmitted by the hub. When received, the data is decrypted by the server software and assigned to the patient's database file. Nurses compare the readings of the individual HF patients and in emergency conditions consult cardiologists for further treatment compliance.

\subsection{Telehealthcare Approach including Health Literacy}

Health Buddy is an electronic device with a high-resolution screen and four large buttons located in patients' homes and connected to remote care managers. The Health Buddy asks patients for vital signs and other health-related information on a daily basis, providing feedback and education based on responses (Kao et al., 2016; Boyne et al., 2011). Health Buddy as part of the Health Buddy Program, not only monitors the patient's vital signs but also educate patients about their disease condition. The questionnaires are structured in order to improve patient's disease-specific knowledge, symptoms and behaviour. The clinical staffs provide feedback on patient's responses and categorize patient's symptoms as a low, medium and high risk (needed further attention).

In TEHAF study (Boyne et al., 2011), the Health Buddy device was used in Dutch (translated by the distribution company) and followed by nurses and doctors according to the European Guidelines. Four programs focussed on self-educating and self-managing of HF patients were conducted. Every program had a different level of monitoring symptoms and education.

The BEAT-HF study (Black et al., 2014 and Ong et al., 2016) uses the Ideal Life equipment (Ideal Life Pod, a Bluetooth-enabled wireless gateway, the Ideal Life Body-Manager and the Ideal Life BP-Manager). Patients are using the devices every day to transmit the data (their weight, blood pressure, heart rate, and responses to 3 symptom questions) that is accessed by the nurses. The nurses contact the patients thru telephone calls in a regular time period or when readings exceed predetermined threshold variables. The BEAT-HF study besides the regular tele-monitoring, includes education of pre-discharge patients. Study nurse educates patients and their family members or caretakers regarding the disease, symptoms, diet, importance of monitoring health parameters, as well as how to use the tele-monitoring equipment.

Motiva Telehealth System is used in the studies of Stut et al. (2015) and Veenstra et al. (2015). This system consists of automated devices for regular measurement of blood pressure, heart rate and weight, and broadband home TV channel which is used to provide patients with educational videos, gentle reminders on medications, surveys on health-related issues and motivational messages for patients' encouragement. The clinicians monitor the patient's basic measurements and contact the patients that require high attention.

In CARME study (Domingo et al., 2012) is also used a version of Motiva system, but patients were divided into 2 groups. Patients in group A were trained with educational videos and motivational messages using Motiva system, whereas patients in group B were additionally using self-monitoring tools (Motiva Plus). The educational videos on different topics related to symptoms, medications, lifestyle, disease conditions, diet, and prevention were played in the Spanish language.

\subsection{Improve Continuity of Care}

In the study of Eilat-Tsanani et al. (2016) the quality of life was measured by Minnesota Living with Heart Failure Questionnaire. The change in the scores of the results indicated an 
improvement in the quality of life of the patients and a decrease in the rate of hospitalization. The BEAT-HF study (Black et al., 2014; Ong et al., 2016) is also using the Minnesota Living with Heart Failure Questionnaire to evaluate the readmission rate and patients' quality of life. According to the results, even though there was no significant difference in the readmission rate, a significant difference in improvement of the quality of life score (at 180-day) was recorded between the intervention and the control participants.

The results from Veenstra et al. (2015) study showed that after telehealth enrolment there were only 32 patients with unplanned HF admissions, and the number of days spent in a hospital was reduced from 975 to 662 days. The quality of life is measured by Minnesota Living with Heart Failure Questionnaire showed that the quality of life of the patient was improved with statistical significance starting from 24 weeks after the enrolment in the program.

In Heart Cycle study (Stut et al., 2015), the self-care behaviours like daily weighing, fluid restriction, low salt diet, medication, and physical activity were assessed using European Heart Failure Self-care Behaviour Scale. The results showed that all self-care behaviours except medication intake, self-reported, and self-care behaviour scores have improved significantly at the end of the study comparing to the beginning.

The results of the CARME study (Domingo et al., 2012) showed that telemedicine program led to a significant reduction in hospital admissions and in the number of days in the hospital for heart failure and also other cardiac causes, as well as to a perception of better quality of life for the patients using both systems (Motiva and Motiva Plus+).

Compliance is another factor which is measured for the intervention group in the DIAL study (Ferrante et al., 2010). During the first 45 days of the trial, there was an improvement in medication compliance for $83 \%$ patients, $40.7 \%$ patients diet compliance and $34.9 \%$ in weight compliance.

In general, there is a high degree of satisfaction with the tele-monitoring tools (Domingo et al., 2012) and the tele-monitoring programs (tools combined with automated education and coaching program) can influence behavioural changes in improving self-care (Stut et al, 2015), patient compliance and adherence (Eliat-Tsanani et al., 2016, Ferrante et al., 2010), as well as improve survival and reduce hospitalization of the patients (Kao et al., 2016, Domingo et al., 2012; Veenstra et al., 2015). Also, need to be mentioned that the results in the study of Blum \& Gottlieb (2014) study indicated that although the 30 days readmission rate for hospitalisation is decreased in the first year, there was no significant change in symptom improvement, mortality, total costs and hospitalizations.

\section{Discussion}

This review emphasizes the significance of including patients from different cultural backgrounds in studies and trials, and the importance for patients to understand spoken language and used technology. Most of the studies include only the patients that speak a particular language, and in some of them, the requirement is the patients to be familiar with the used technology. This aligns with the ASQFHC area of action related to the cultural background. Provided review supports the assumption that (pre-prepared) information translated into languages (understandable for patients) can provide effective and respectful communication between patients and health care workers. 
Considering the consumer-centred principle of ASQFHC related to the developing methods and models to help patients get health services when they need them, tele-monitoring is one approach that can ease the communication between the patients and health care professionals and provide greater access to the health services. Besides the communication and access to services, reviewed tele-monitoring systems offer educational materials and provide information regarding the health condition of the patients. Thus, can be as well used as a health literacy tool.

Based on the ASQFHC, improving the continuity of care has a positive effect on the care provided to the patients. There are several examples in the presented literature review that measure the improvement of the quality of life of the monitored patients. According to these studies, increasing the quality of life is one of the major benefits of tele-monitoring systems. Additionally, monitoring and qualitative analysis (framing questions and collecting user views) improve patient's self-care and self-confidence, as well as the compliance with the diet, exercises regime and medication adherence.

The review also indicated that tele-monitoring systems allow patients to track their baseline measurements and identify the importance of self-care and self-compliance, support and advance the practitioner-patient relationship, provide information regarding the disease's symptoms and management thus strengthen the patients' competence and increase their confidence.

\section{Conclusion}

The most notable gaps found in this review were patients' adoption and usage of technology, improper training and insufficient communication between clinicians and patients. Also, challenges like socio-economic status and low health literacy can additionally contribute towards poor congestive heart failure conditions and health care utilization. The health care providers can contribute in bridging these gaps, supporting the patients' participation in the health care by explaining the functionalities and outcomes, as well as the health literacy goals of the tele-monitoring systems.

Based on the literature review conducted in this paper, tele-monitoring systems support patients' autonomy, competence and relatedness, and empower the patients' self-care promoting motivation, education and self-management. Thus provide consumer-centred health care, oriented towards patients' safety and improved quality of life.

The Australian Safety and Quality Framework for Health Care describes a vision for safe and high-quality care for all Australians and sets out the actions needed to achieve this vision. Although the papers reviewed are studies conducted outside Australia, we can conclude that the Framework can be applied in the usage of the tele-monitoring technology for the management of patients with congestive heart failure.

\section{References}

Australian Commission on Safety and Quality in Health Care. (2010). Australian Safety and Quality Framework for Health Care. Retrieved from http://www.safetyandquality.gov.au/national-priorities/australian-safety-and-qualityframework-for-health-care. 
Black, J. T., Romano, P. S., Sadeghi, B., Auerbach, A. D., Ganiats, T. G., Greenfield, S., ... \& Ong, M. K. (2014). A remote monitoring and telephone nurse coaching intervention to reduce readmissions among patients with heart failure: study protocol for the Better Effectiveness After Transition-Heart Failure (BEAT-HF) randomized controlled trial. Trials, 15(1), 124.

Blum, K., \& Gottlieb, S. S. (2014). The effect of a randomized trial of home telemonitoring on medical costs, 30-day readmissions, mortality, and health-related quality of life in a cohort of community-dwelling heart failure patients. Journal of cardiac failure, 20(7), 513521.

Boyne, J. J., Vrijhoef, H. J., De Wit, R., \& Gorgels, A. P. (2011). Telemonitoring in patients with heart failure, the TEHAF study: Study protocol of an ongoing prospective randomised trial. International journal of nursing studies, 48(1), 94-99.

Burrows, A., Coyle, D., \& Gooberman-Hill, R. (2018). Privacy, boundaries and smart homes for health: An ethnographic study. Health \& place, 50, 112-118.

Cheow, M. F., \& Win, K. T. (2007). Personal health record and healthcare systems. International journal of healthcare technology and management, 8(3-4), 209-225.

Cichosz, S. L., Ehlers, L. H., \& Hejlesen, O. (2016). Health effectiveness and cost-effectiveness of telehealthcare for heart failure: study protocol for a randomized controlled trial. Trials, 17(1), 590.

Domingo, M., Lupón, J., González, B., Crespo, E., López, R., Ramos, A., \& Bayes-Genis, A. (2012). Evaluation of a telemedicine system for heart failure patients: feasibility, acceptance rate, satisfaction and changes in patient behavior: results from the CARME (CAtalan Remote Management Evaluation) study. European Journal of Cardiovascular Nursing, 11(4), 410-418.

Duckett, S. (2017). Review of hospital safety and quality assurance in Victoria. Retrieved from https://www2.health.vic.gov.au/about/publications/researchandreports/report-of-thereview-of-hospital-safety-and-quality-assurance-in-victoria

Eilat-Tsanani, S., Golovner, M., Marcus, O., Dayan, M., Sade, Z., Iktelat, A., ... \& Oppenheimer, Y. (2016). Evaluation of telehealth service for patients with congestive heart failure in the north of Israel. European Journal of Cardiovascular Nursing, 15(3), e78-e84.

Ferrante, D., Varini, S., Macchia, A., Soifer, S., Badra, R., Nul, D., ... \& GESICA Investigators. (2010). Long-term results after a telephone intervention in chronic heart failure: DIAL (Randomized Trial of Phone Intervention in Chronic Heart Failure) follow-up. Journal of the American College of Cardiology, 56(5), 372-378.

Gunnell, K.E., Crocker, P.R., Mack, D.E., Wilson, P.M. and Zumbo, B.D., 2014. Goal contents, motivation, psychological need satisfaction, well-being and physical activity: A test of self-determination theory over 6 months. Psychology of Sport and Exercise, 15(1), pp.19-29.

Hancox, J. E., Quested, E., Ntoumanis, N., \& Thøgersen-Ntoumani, C. (2018). Putting selfdetermination theory into practice: application of adaptive motivational principles in the exercise domain. Qualitative Research in Sport, Exercise and Health, 10(1), 75-91.

Kao, D. P., Lindenfeld, J., Macaulay, D., Birnbaum, H. G., Jarvis, J. L., Desai, U. S., \& Page, R. L. (2016). Impact of a telehealth and care management program on all-cause mortality 
and healthcare utilization in patients with heart failure. Telemedicine and e-Health, 22(1), $2-11$.

Legault, L. (2017). Self-determination theory. Encyclopedia of Personality and Individual Differences, 1-9.

Liberati, A., Altman, D. G., Tetzlaff, J., Mulrow, C., Gøtzsche, P. C., Ioannidis, J. P., ... \& Moher, D. (2009). The PRISMA statement for reporting systematic reviews and meta-analyses of studies that evaluate health care interventions: explanation and elaboration. PLoS medicine, 6(7), e1000100.

Maarop N., \& Win K.T. (2012). Understanding the need of healthcare providers for teleconsultation and technology attributes in relation to the acceptance of teleconsultation in Malaysia: a mixed methods study, Journal of Medical Systems, 36(5) , 2881-2892,

Murray, A., Hall, A. M., Williams, G. C., McDonough, S. M., Ntoumanis, N., Taylor, I. M., ... \& Lonsdale, C. (2015). Effect of a Self-Determination Theory-Based Communication Skills Training Program on Physiotherapists' Psychological Support for Their Patients With Chronic Low Back Pain: A Randomized Controlled Trial. Archives of physical medicine and rehabilitation, 96(5), 809-816.

Ng, J. Y., Ntoumanis, N., Thøgersen-Ntoumani, C., Deci, E. L., Ryan, R. M., Duda, J. L., \& Williams, G. C. (2012). Self-determination theory applied to health contexts: A metaanalysis. Perspectives on Psychological Science, 7(4), 325-340.

Ong, M. K., Romano, P. S., Edgington, S., Aronow, H. U., Auerbach, A. D., Black, J. T., ... \& Ganiats, T. G. (2016). Effectiveness of remote patient monitoring after discharge of hospitalized patients with heart failure: the better effectiveness after transition-heart failure (BEAT-HF) randomized clinical trial. JAMA internal medicine, 176(3), 310-318.

Ponikowski, P., Anker, S. D., AlHabib, K. F., Cowie, M. R., Force, T. L., Hu, S., ... \& Samal, U. C. (2014). Heart failure: preventing disease and death worldwide. ESC Heart Failure, 1(1), 4-25.

Ryan, R. M., \& Deci, E. L. (2000). Self-determination theory and the facilitation of intrinsic motivation, social development, and well-being. American psychologist, 55(1), 68.

Ryan, R. M., Patrick, H., Deci, E. L., \& Williams, G. C. (2008). Facilitating health behaviour change and its maintenance: Interventions based on self-determination theory. European Health Psychologist, 10(1), 2-5.

Stut, W., Deighan, C., Cleland, J. G., \& Jaarsma, T. (2015). Adherence to self-care in patients with heart failure in the HeartCycle study. Patient preference and adherence, 9, 1195.

Trajkovik, V., Koceski, S., Vlahu-Gjorgievska, E., \& Kulev, I. (2014). Collaborative Health-Care System (COHESY) Model. In S. Adibi (Ed.), mHealth Multidisciplinary Verticals (pp. 123140). CRC Press.

Tripoliti, E. E., Papadopoulos, T. G., Karanasiou, G. S., Kalatzis, F. G., Bechlioulis, A., Goletsis, Y., ... \& Fotiadis, D. I. (2017). Estimation of New York Heart Association class in heart failure patients based on machine learning techniques. In IEEE EMBS International Conference on Biomedical \& Health Informatics, 421-424. IEEE. 
Veenstra, W., Op den Buijs, J., Pauws, S., Westerterp, M., \& Nagelsmit, M. (2015). Clinical effects of an optimised care program with telehealth in heart failure patients in a community hospital in the Netherlands. Netherlands Heart Journal, 23(6), 334-340.

Velagaleti, R. S., \& Vasan, R. S. (2007). Heart failure in the twenty-first century: is it a coronary artery disease or hypertension problem? Cardiology clinics, 25(4), 487-495.

Ware, P., Seto, E., \& Ross, H. J. (2018). Accounting for complexity in home telemonitoring: a need for context-centred evidence. Canadian Journal of Cardiology, 34(7), 897-904.

Zipes, D. P., Libby, P., Bonow, R. O., Mann, D. L., \& Tomaselli, G. F. (2018). Braunwald's Heart Disease E-Book: A Textbook of Cardiovascular Medicine. Elsevier Health Sciences.

Copyright: (C) 2019 Vlahu-Gjorgievska, Nagapuri \& Win. This is an open-access article distributed under the terms of the Creative Commons Attribution-NonCommercial 3.0 Australia License, which permits non-commercial use, distribution, and reproduction in any medium, provided the original author and AJIS are credited.

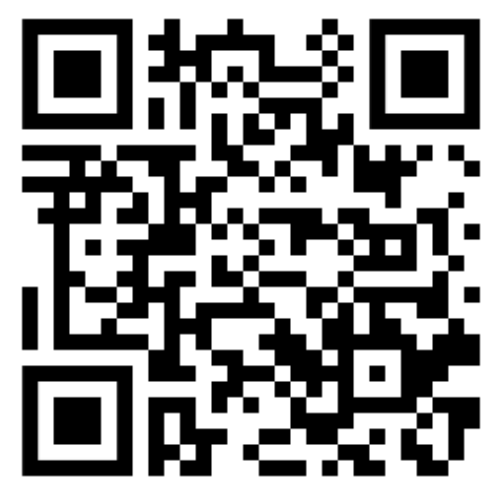

